\title{
MORPHOLOGICAL STUDY OF HUMAN LUNGS
}

\section{Subhalakshmi Wahengbam ${ }^{1}$, Huidrom Rajshree Devi *2, Gurumayum Tarunkumar Sharma ${ }^{3}$, Gaining Gangmei ${ }^{2}$, Ningthoujam Debashree Devi ${ }^{4}$.}

${ }^{1}$ Professor, Department of Anatomy, Jawaharlal Nehru Institute of Medical Sciences (JNIMS), Porompat, Imphal, Manipur, India.

${ }^{*}$ Assistant Professor, Department of Anatomy, Jawaharlal Nehru Institute of Medical Sciences (JNIMS), Porompat, Imphal, Manipur, India.

${ }^{3}$ Demonstrator, Department of Anatomy, Jawaharlal Nehru Institute of Medical Sciences (JNIMS), Porompat, Imphal, Manipur, India.

${ }^{4}$ Assistant Professor, Department of Pharmacology, Jawaharlal Nehru Institute of Medical Sciences (JNIMS), Porompat, Imphal, Manipur.

\section{ABSTRACT}

Background and aims: Knowledge of anatomical variations in lung morphology is not only of academic interest but is essential during surgery and also while interpreting various radiological images. The present study was undertaken with the aim to observe the variations of lung morphology.

Materials and Methods: The shape of the lungs, variations of fissures, lobes and hilar structures were studied in 42 right and 37 left isolated lungs.

Results: Unusual shape was seen in 4 lungs. Among the right lungs, oblique fissure was incomplete in $42.86 \%$ and absent in $7.14 \%$ and horizontal fissure was incomplete in $61.90 \%$ and absent in $19.05 \%$. Inferior accessory fissure (IAF) was present in $21.43 \%$ and superior accessory fissure (SAF) in $7.14 \%$. Usual right hilar architecture having a pulmonary artery with 2 pulmonary veins and 2 bronchi was not seen in any case however, the usual architecture with a superior lobar artery was seen in $28.57 \%$ cases. Among the left lungs, oblique fissure was incomplete in $40.54 \%$ and absent in $2.70 \%$. Horizontal fissure was present in $24.32 \%$, left minor fissure (LMF) in $29.73 \%$, inferior accessory fissure (IAF) in $43.24 \%$ and superior accessory fissure (SAF) in $2.70 \%$. Usual left hilar architecture having a pulmonary artery, 2 pulmonary veins and a bronchus was seen in $54.06 \%$.

Conclusion: The knowledge of variations in the lung morphology observed in this study will be of academic interest and also useful for diagnostic and clinical management of pulmonary and even cardiac cases.

KEY WORDS: Fissures, Lobes, Hilum, Broncho-pulmonary segments.

Address for Correspondence: Dr. Huidrom Rajshree Devi, Department of Anatomy, Jawaharlal Nehru Institute of Medical Sciences (JNIMS), Porompat, Imphal, Manipur. Pin no: 795005.

Mobile no: 08731086918. E-Mail: subhawah_e@rediffmail.com

Access this Article online

Quick Response code

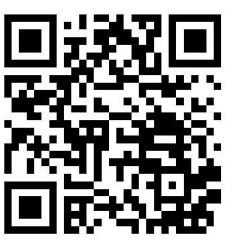

DOI: $10.16965 /$ ijar.2019.115
Journal Information

\section{International Journal of Anatomy and Research}

ICV for 2016 ISSN (E) 2321-4287 | ISSN (P) 2321-8967

90.30 https://www.ijmhr.org/ijar.htm

DOI-Prefix: https://dx.doi.org/10.16965/ijar

\section{Article Information}

Received: 17 Jan 2019

Peer Review: 18 Jan 2019

Revised: None
Accepted: 07 Mar 2019

Published (O): 05 Apr 2019

Published (P): 05 Apr 2019

\section{INTRODUCTION}

The lungs are the essential organs of respiration, approximately half conical in shape. The left lung is divided into superior and inferior lobes by an oblique fissure and the right lung into superior, middle and inferior lobes by oblique and horizontal fissures [1]. The fissures facilitate the movement of the lobes in relation to one another, 
which accommodates the greater distention and movement of the lower lobes during respiration. Thus, they help in a more uniform expansion of the whole lung [2] The fissures may be complete, when the lobes remain held together only at the hilum by the bronchi and pulmonary vessels, or they may be incomplete when there are areas of parenchymal fusion between the lobes or they may be absent altogether [3].

Anatomically, an accessory fissure is a cleft of varying depth lined by visceral pleura [4] and it usually occurs at the boundaries of the bronchopulmonary segments [5]. Radiologically, an accessory fissure appears as a thin white line, resembling the major or minor fissure, except for its location [5] and it can be mistaken for a lung lesion [6]. The most commonly observed accessory fissures are inferior accessory fissure, superior accessory fissure and left minor fissure [5]. They are commonly observed in lung specimens, but are often unappreciated or misinterpreted on radiographs and computerized tomographic (CT) scans because of their incompleteness, thick sections and orientation to a particular plane [7].

Major structures of the lung root that enter or leave the hilum are similarly arranged on both sides with superior pulmonary vein anteriorly; and pulmonary artery and principal bronchus more posteriorly. From superior to inferior, the usual sequence on right hilum is: superior lobar (eparterial) bronchus, pulmonary artery, principal bronchus and inferior pulmonary vein; and on left hilum: pulmonary artery, principal (hyparterial) bronchus and inferior pulmonary vein. The arrangement of bronchopulmonary segments and the pulmonary hila permit resection of abscesses and localised primary lung malignancy [1].

Considering the anatomical and clinical importance of this topic, the present study was undertaken to observe the morphology of the lung in Indian population and to determine the variations of shape, fissures, lobes and major hilar structures.

\section{MATERIALS AND METHODS}

Seventy nine isolated, formalin fixed lungs (42 right and 37 left) from adult Indian cadavers of unknown age and sex, preserved in the dissection hall of Anatomy department of Jawaharlal Nehru Institute of Medical Sciences (JNIMS), Imphal were studied. The specimens having pathological lesions, marks of previous surgery and those that were damaged during removal were excluded from the study. Shape of lungs, number of fissures and lobes and variations in the major hilar structures were observed and photographed.

The anatomical classification proposed by Craig and Walker [8] as given under was followed to determine the completeness of fissures.

\section{Craig and Walker's fissural classification:}

Grade I- complete fissure with entirely separate lobes;

Grade-II- complete visceral cleft but parenchymal fusion at the base of the fissure;

Grade III- visceral cleft evident for a part of the fissure and

Grade IV- complete fusion of lobes with no evident fissural line.

\section{RESULTS}

Unusual shapes were seen in 4 cases. 2 lungs, one of each side had a flattened shape (Fig.2d) and another 2, also one of each side had a slightly cylindrical shape (Fig.3c).

The incidence of the oblique and horizontal fissures of the lungs are shown in Table 1 and incidence of accessory fissures of the lungs in Table 2.

Right lungs: There was a case of single-lobed right lung (Fig.1d) and 9 cases of 2-lobed right lung due to the absence of oblique fissure (Fig.3b) in 2 cases and horizontal fissure (Fig.3c) in 7 cases. One right lung had 5 imperfect lobes due to the presence of two accessory fissures cutting the horizontal fissure almost perpendicularly (Fig.3a). All together 24 accessory fissures were present in 13 right lungs, out of which, 3 were superior accessory fissure (SAF) demarcating a dorsal lobe(Fig.4a) and 9 were inferior accessory fissure (IAF) which demarcated an infracardiac lobe (Fig.4b) in all the cases except in one. Only 23 right lungs (54.76\%) were having the normal 3 lobes without any accessory fissure; amongst these only 7 right lungs $(16.67 \%)$ had 3 perfect lobes separated by complete horizontal and oblique fissures 
(Fig.1a) while in the remaining, the lobes were imperfect due to incompleteness of either the oblique or horizontal fissure or both the fissures (Fig. 1b \&1c).

Fig. 1: Photographs of right lungs showing the four different grades of oblique $\&$ horizontal fissures: Fig. 1a: Grade I, Fig.1b: Grade II, Fig.1c: Grade III \& Fig.1d: Grade IV. Fig.1d is a case of single lobed right lung.

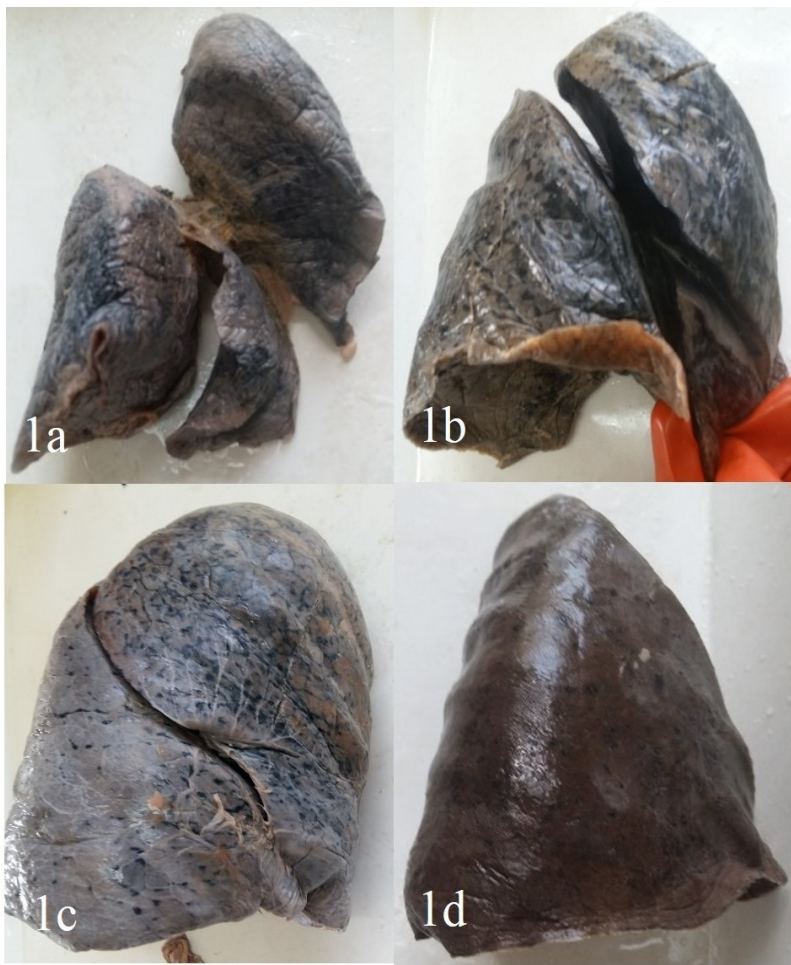

Fig. 2: Photographs of left lungs showing the four different grades of oblique fissure: Fig. 2a: Grade I, Fig. 2b: Grade II, Fig. 2c: Grade III \& Fig.2d: Grade IV. Fig.2d: is a case of singled lobe left lung $\&$ also with an unusual flattened shape.

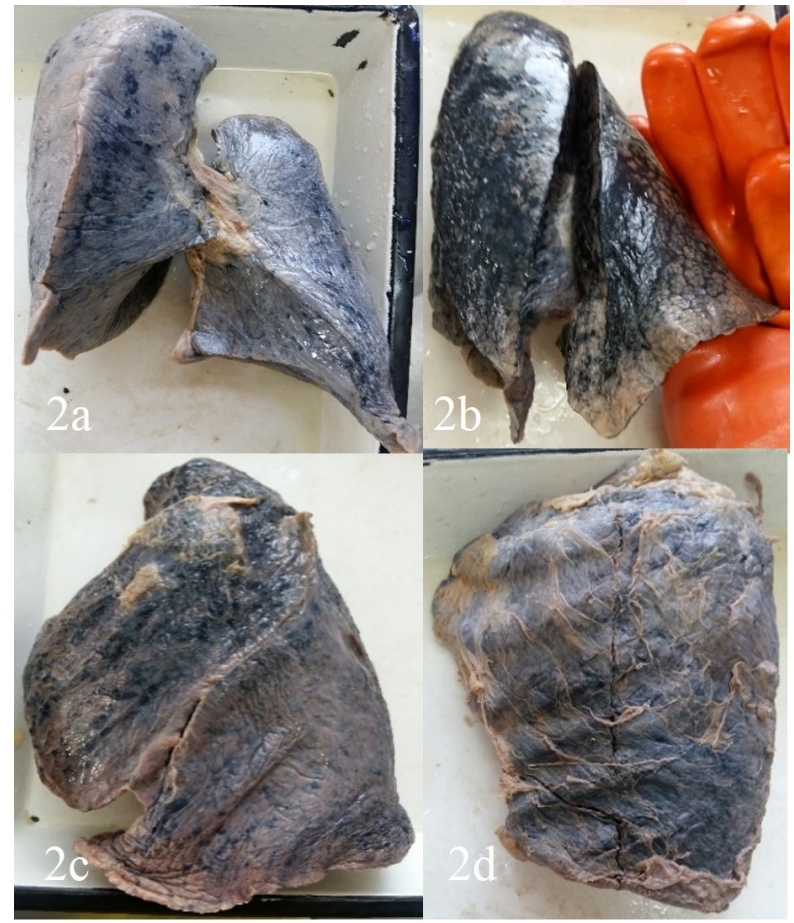

Fig. 3: Photographs of lungs showing variations of lung lobes: Fig. 3a: 5-lobed right lung due to the presence of 2 accessory fissures cutting the horizontal fissure almost perpendicularly, Fig.3b: 2-lobed right lung due to absence of oblique fissure, Fig.3c: 2-lobed slightly cylindrical right lung due to absence of horizontal fissure, Fig.3d: 3-lobed left lung due to the presence of an accessory, incomplete horizontal fissure.

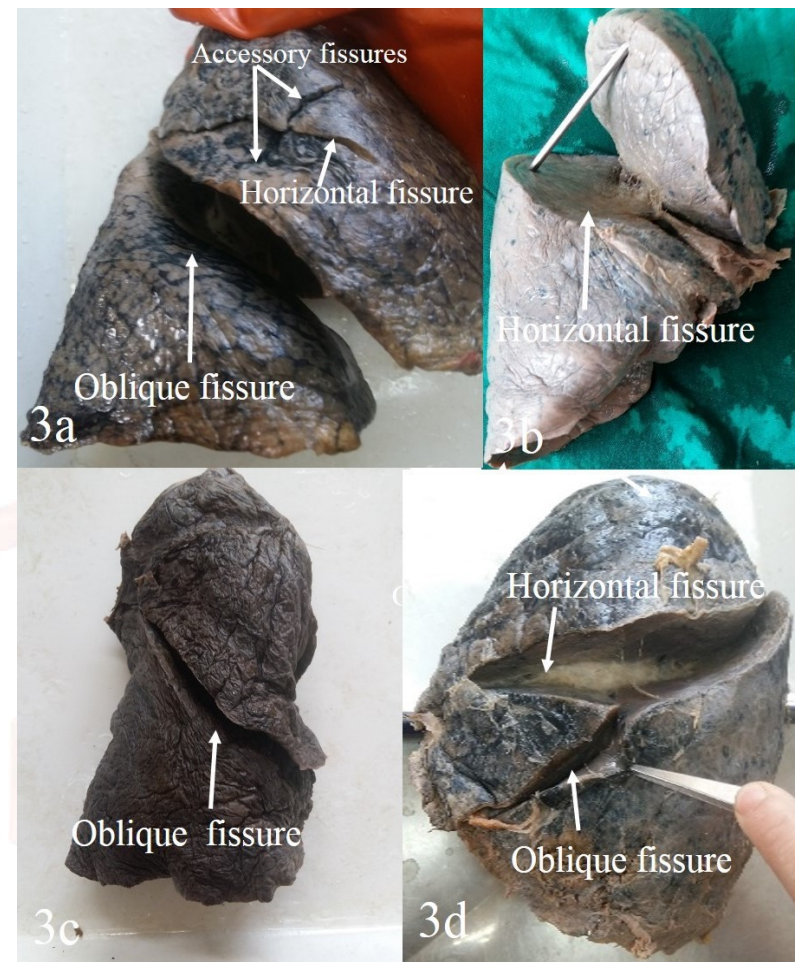

Fig.4: Photographs of lungs showing accessory fissures: Fig.4a: right lung with a SAF demarcating a dorsal lobe (DL), Fig.4b: right lung with IAF demarcating an infracardiac lobe, Fig.4c: left lung with a SAF demarcating a dorsal lobe (DL) and a common accessory fissure perpendicular to the oblique fissure, Fig.4d: left lung with IAF demarcating an infracardiac (IC) lobe, Fig. 4e: left lung with LMF separating the lingula from the rest of upper lobe.

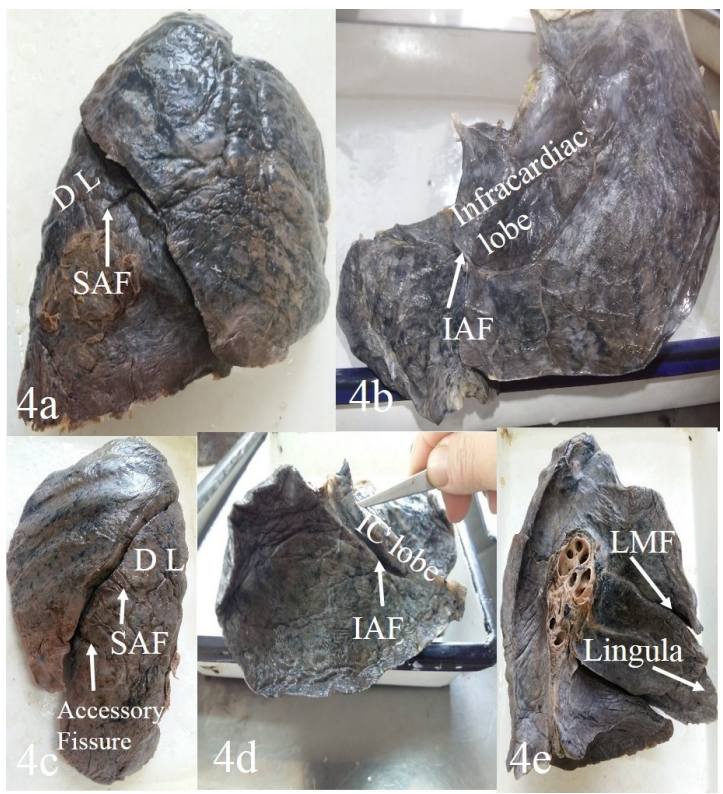


Fig.5: Photographs of lung hila: Fig.5a: normal left hilar structures with 1 pulmonary artery, 2 pulmonary veins \& 1 bronchus. Fig.5b: minimal left hilar structures with just a single artery, vein \& bronchus each. Fig.5c: multiple left hilar structures with 3 arteries, 7 veins \& 2 bronchi. Fig.5d: commonest right hilar structures with 2 arteries, veins \& bronchii each. Fig.5e: multiple right hilar structures with 3 arteries, 5 veins \& 3 bronchi; middle lobar vein has a separate exit. Fig.5f: right hilum showing a separate exit of middle lobar vein. Fig.5g: right hilum showing a separate exit of middle lobar vein which drains into inferior pulmonary vein.

Colour code: artery: blue, vein: red, bronchus: yellow.

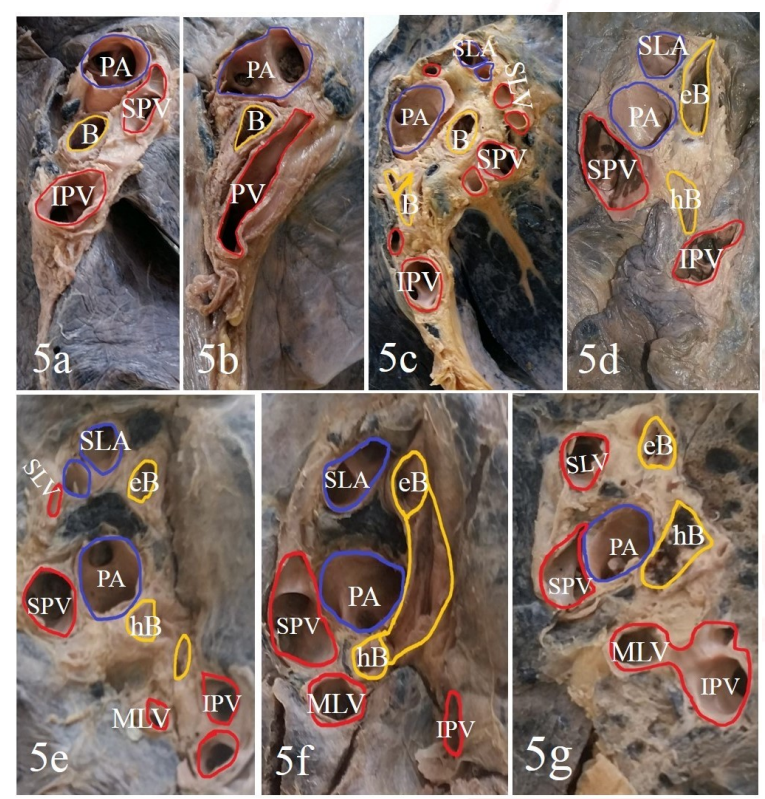

Note: PA: Pulmonary Artery, SLA: Superior Lobar Artery, PV: Pulmonary Vein, SPV: Superior Pulmonary Vein, IPV: Inferior Pulmonary Vein, SLV: Superior Lobar Vein, MLV: Middle Lobar Vein, B: Bronchus, eB: eparterial Bronchus, hB: hyparterial Bronchus.

Left lungs: There was a case of single-lobed left lung (Fig. 2d). The horizontal fissure was present in 9 left lungs out of which only one met the oblique fissure resulting in a 3-lobed left lung (Fig. 3d). All together 51 extra fissures including the unusual horizontal fissure were present in
27 left lungs, out of which 1 was SAF demarcating a dorsal lobe (Fig. 4c) and 16 were IAF which demarcated an infracardiac lobe (Fig. 4d) in 13 cases and 11 were left minor fissure (LMF), separating the lingula from the rest of the upper lobe; 5 of which met the horizontal fissure (Fig. $4 \mathrm{e})$. Of the remaining 14 accessory fissures, the most common (10 in number) was a fissure perpendicular to the oblique fissure (Fig. 4c). Only 9 left lungs (24.32\%) were having the normal 2 lobes without any horizontal or accessory fissure; amongst these only 6 left lungs(16.22\%) had 2 perfect lobes separated by complete oblique fissure(Fig.2a) while in the remaining, the lobes were imperfect due to incompleteness of the oblique fissure(Fig.2b \& 2c).

Hilar morphology: The variations in major structures present in the lung hila are shown in Table 3.

Right hilum: Usual structures i.e. a pulmonary artery, 2 pulmonary veins and 2 bronchi was not observed in any of the cases. However, the usual structures with an additional superior lobar artery was observed in $28.57 \%$ cases (Fig. $5 d$ ) and one hilum had as many as 3 arteries, 5 veins and 3 bronchi (Fig.5e). Right middle lobar vein had independent exit in 7 cases(Fig. 5e, 5f, 5g), out of which 3 were seen to drain into right inferior pulmonary vein (Fig. $5 \mathrm{~g}$ ).

Left hilum: Usual structures i.e. a pulmonary artery, 2 pulmonary veins and a bronchus was observed in $54.06 \%$ (Fig.5a). One had just a single artery, vein and bronchus each (Fig. 5b) and another had as many as 3 arteries, 7 veins and 2 bronchi (Fig.5c).

Table 1: Incidence of oblique and horizontal fissures of lungs based on Craig \& Walker's classification.

\begin{tabular}{|c|c|c|c|c|c|c|c|c|c|c|c|}
\hline \multirow{2}{*}{ Lung } & \multirow{2}{*}{ Fissure } & \multicolumn{2}{|c|}{ Grade I } & \multicolumn{2}{c|}{ Grade II } & \multicolumn{2}{c|}{ Grade III } & \multicolumn{2}{c|}{ Grade IV } & \multicolumn{2}{|c|}{ Total } \\
\cline { 3 - 13 } & & No. & $\%$ & No. & $\%$ & No. & $\%$ & No. & $\%$ & No. & $\%$ \\
\hline \multirow{2}{*}{ Right } & Oblique & 21 & 50 & 3 & 7.14 & 15 & 35.72 & 3 & 7.14 & 42 & 100 \\
\cline { 2 - 14 } & Horizontal & 8 & 19.05 & 3 & 7.14 & 23 & 54.76 & 8 & 19.05 & 42 & 100 \\
\hline \multirow{2}{*}{ Left } & Oblique & 21 & 56.76 & 6 & 16.22 & 9 & 24.32 & 1 & 2.7 & 37 & 100 \\
\cline { 2 - 13 } & Horizontal & - & - & - & - & 9 & 24.32 & - & - & 9 & 24.32 \\
\hline
\end{tabular}

Table 2: Incidence of accessory fissures of lungs based on Craig \& Walker classification.

\begin{tabular}{|c|c|c|c|c|c|c|c|c|c|c|c|}
\hline \multirow{2}{*}{ Lung } & \multirow{2}{*}{ Fissure } & \multicolumn{2}{|c|}{ Grade I } & \multicolumn{2}{c|}{ Grade II } & \multicolumn{2}{c|}{ Grade III } & \multicolumn{2}{c|}{ Grade IV } & \multicolumn{2}{c|}{ Total } \\
\cline { 3 - 12 } & & No. & $\%$ & No. & $\%$ & No. & $\%$ & No. & $\%$ & No. & $\%$ \\
\hline \multirow{2}{*}{ Right } & SAF & - & - & - & - & 3 & $7.14 \%$ & - & - & 3 & $7.14 \%$ \\
\cline { 2 - 13 } & IAF & 1 & $2.38 \%$ & 2 & $4.76 \%$ & 6 & $14.29 \%$ & - & - & 9 & $21.43 \%$ \\
\hline \multirow{3}{*}{ Left } & SAF & & - & - & - & 1 & $2.70 \%$ & - & - & 1 & $2.70 \%$ \\
\cline { 2 - 12 } & IAF & & - & 4 & $10.81 \%$ & 12 & $32.43 \%$ & - & - & 16 & $43.24 \%$ \\
\cline { 2 - 12 } & LMF & & - & 1 & $2.70 \%$ & 10 & $27.03 \%$ & - & - & 11 & $29.73 \%$ \\
\hline
\end{tabular}


Table 3: Variations in major structures present in the lung hila.

\begin{tabular}{|c|c|c|c|c|c|c|c|c|c|c|}
\hline \multirow{2}{*}{ Lung hilum } & \multicolumn{3}{|c|}{ Number of artery } & \multicolumn{3}{c|}{ Number of vein } & \multicolumn{3}{c|}{ Number of bronchus } \\
\cline { 2 - 11 } & $\mathbf{1}$ & $\mathbf{2}$ & $\mathbf{> 2}$ & $\mathbf{1}$ & $\mathbf{2}$ & $\mathbf{2}$ & $\mathbf{1}$ & $\mathbf{2}$ & $>\mathbf{2}$ \\
\hline Right & No. & 9 & 29 & 4 & 3 & 22 & 17 & 7 & 31 & 4 \\
\hline Left & No. & 34 & 2 & 1 & 4 & 21 & 12 & 29 & 7 & 1 \\
\hline
\end{tabular}

Table 4: Comparison of incidence of variations of lung fissures with previous studies.

\begin{tabular}{|c|c|c|c|c|c|c|}
\hline \multirow{2}{*}{ Authors } & \multicolumn{4}{|c|}{ Right lung } & \multicolumn{2}{c|}{ Left lung } \\
\cline { 2 - 7 } & Oblique fissure & Horizontal fissure & \multicolumn{2}{c|}{ Oblique fissure } \\
\cline { 2 - 7 } & Incomplete & Absent & Incomplete & Absent & Incomplete & Absent \\
\hline Medlar [10] & $25.60 \%$ & $4.80 \%$ & $62.30 \%$ & - & $10.60 \%$ & $7.30 \%$ \\
\hline Lukose et al [11] & - & - & $21 \%$ & $10.50 \%$ & $21 \%$ & - \\
\hline Meenakshi et al [3] & $36.6 \%-$ & - & $63.30 \%$ & $16.60 \%$ & $46.60 \%$ & - \\
\hline Prakash et al [12] & $39.30 \%$ & $7.10 \%$ & $50 \%$ & $7.10 \%$ & $35.70 \%$ & $10.70 \%$ \\
\hline Quadros et al [13] & $5.55 \%$ & $0 \%$ & $25.00 \%$ & $11.11 \%$ & $2.50 \%$ & $0 \%$ \\
\hline George BM et al [9] & $3.07 \%$ & $0 \%$ & $35.38 \%$ & $23.05 \%$ & $5.06 \%$ & $0 \%$ \\
\hline Present study & $42.86 \%$ & $7.14 \%$ & $61.90 \%$ & $19.05 \%$ & $40.54 \%$ & $2.70 \%$ \\
\hline
\end{tabular}

Table 5: Comparison of incidence of accessory fissures of lungs with previous studies.

\begin{tabular}{|c|c|c|c|c|c|}
\hline \multirow{2}{*}{ Authors } & \multicolumn{2}{|c|}{ Right lung } & \multicolumn{3}{c|}{ Left lung } \\
\cline { 2 - 6 } & SAF & IAF & SAF & IAF & LMF \\
\hline Nene et al [14] & $4 \%$ & $14 \%$ & $0 \%$ & $24 \%$ & $26 \%$ \\
\hline Quadros et al [13] & $8.33 \%$ & $5.55 \%$ & $0 \%$ & $5.00 \%$ & $17.50 \%$ \\
\hline Present study & $7.14 \%$ & $21.43 \%$ & $2.70 \%$ & 43.24 & $29.73 \%$ \\
\hline
\end{tabular}

\section{DISCUSSION}

Though there are many studies on lung morphology, its shape is often ignored except for the study by George et al [9] which reported leaf like gross appearance in 5 cases and cylindrical appearance in 2 cases. In the present study, unusual shapes were seen in 4 cases. The present study supports the statement of George et al [9] that the shape anomaly may be of congenital cause and when exists, might cause confusions in radiological diagnosis.

Comparison of variations of lung fissures with previous studies in Table 4 shows that the present study had a higher incidence of incomplete as well as absent lung fissures, both oblique and horizontal fissures on right lung and oblique fissure on left lung than that of the majority of the studies. The present study observed that the fissures were incomplete more on the right side than on the left and the incidence of incomplete horizontal fissure was more than that of the oblique fissure on the right side. These findings are consistent with those of the majority of the studies.

Comparison of the incidence of the common accessory fissures of the lungs with previous studies in Table 5 shows a higher incidence in the present study except for the right SAF which was found to be higher in the study by Quadros et al [13]. The superior accessory fissure (SAF) partially or completely separates the superior segment of the lower lobe from the basal segments which is then called the posterior or dorsal lobe. Incidence of superior accessory fissure is found to be $5-30 \%$ in autopsy studies whereas high resolution CT scan detects it to be $3 \%$ [5]. In our study, it was observed in $7.14 \%$ of right lung and $2.70 \%$ of left lung. Further, it is reported to be more common in right lung as compared to left on $\mathrm{e}^{5}$ which is consistent with our finding. The inferior accessory fissure (IAF) surrounds the medial basal segment of the lower lobe. When demarcated from the rest of the lower lobe, this segment has been called the cardiac, inferior accessory, retrocardiac, or infracardiac lobe [5]. In the present study, 8 IAF out of 9 on right and 13 IAF out of 16 on left demarcated an infracardiac lobe. The present study supports the observation of Godwin and Tarver [5] that the most common accessory fissures are the inferior accessory fissure as it was observed in $31.65 \%$ of the specimens ( $21.43 \%$ on right and $43.24 \%$ on left) in the present study. A left minor fissure (LMF) separates the lingula from the rest of the left upper lobe $^{5}$. In the present study LMF stood out to be the $2^{\text {nd }}$ most frequently occurring accessory fissure seen in $29.73 \%$ of specimens. 
Embryological basis of variations of lung fissures: During the development, as the lung grows, the spaces or fissures that separate individual bronchopulmonary buds/segments become obliterated except along two planes, evident in the fully developed lungs as oblique or horizontal fissures. Absence or incomplete oblique or horizontal fissures could be due to obliteration of these fissures either completely or partially. Accessory fissure could be the result of non-obliteration of spaces between the bronchopulmonary buds which normally are obliterated [15]. Moreover, the presence of fissures perpendicular to the oblique fissure which was observed as one of the common accessory fissure in the present study may imply that the fusion of bronchopulmonary segments proceeds towards the main fissure which often remain incomplete and thus persist as such fissures.

Clinical significance of variations of lung fissures: The awareness of the variations of the lung fissures is essential as they form the boundaries for the lobes of the lungs. Incomplete separation of the lobes and the identification of completeness of fissures are important prior to performing lobectomies because individuals with incomplete fissures are more prone to develop postoperative air leaks and may require further procedures such as stapling or pericardial sleeves [1]. The gradation of fissure is important while performing lobectomy and video assisted thoracoscopic surgery since the vessels and bronchi need to be ligated by approaching through the depth of the fissure and thus Grade 1 oblique fissure facilitates such approach [16]. Otherwise the lung parenchyma has to be dissected to reach those structures leading to intra-operative haemorrhage and more postoperative complications [17]. On the other hand, while performing right upper lobectomy, if the oblique fissure is of Grade 1 variety, preventive fixation of the middle lobe is essential to prevent its torsion [18].

Incomplete fissures may alter the spread of disease within the lung. Pneumonia in particular lobe is often limited to that lobe alone by the fissures. In patients with incomplete fissures, pneumonia may spread to adjacent lobes through the incomplete fissures. Odd lobar involvement with carcinoma of the lung may be explained on a similar basis [19].

Knowledge of different types of accessory fissures is important because it may can be mistakenly confused with areas of linear atelectasis, pleural scars or walls of bullae [5]. It might alter usual pattern of lung collapse in patients with endobronchial lesion and pose difficulty in diagnosing the extent of lesion [19]. It may act as a barrier to spread of infection, creating a sharply marginated pneumonia which can wrongly be interpreted as atelectasis or consolidation [5].

Hilar structures: There are only a few studies on the hilar anatomy of the lungs though there are many studies on the fissures and the lobar pattern of the lungs. The present study supports the observation of Murlimanju et al [20] that pulmonary hilar morphology is extremely variable however, refutes their observation that the variations were higher in the left lung (48.2\%) than the right lungs (16.1\%) since in the present study, the variations were observed more on the right lungs (100\%) than the left lungs (45.06\%). Anatomical variations of the pulmonary artery increase the risks for vessel injury and critical mistakes during pulmonary artery resection [21]. Subotich et al [22] reported that $16.4 \%$ of patients had pulmonary vessel variations and $47.8 \%$ of these variations occurred in the left lung. However, in the present study, pulmonary artery variations were observed in $78.57 \%$ of right hilum and only $8.11 \%$ of left hilum.

In the present case, pulmonary vein variation was observed in $47.62 \%$ of right lungs and 42.24 $\%$ of left lungs which is comparable with the finding of $46.03 \%$ of variations in pulmonary venous anatomy of dissected lungs observed in a study [23]. The pulmonary veins are the dominant source of ectopic depolarization initiating atrial fibrillation in the majority of patients with paroxysmal atrial fibrillation [24]. The frequency of atrial arrhythmias is high in patients with separate ostium for the right middle lobar vein than those with other patterns [25]. In addition, the anatomic variation of middle lobar vein draining into the inferior pulmonary vein is surgically important because right inferior pulmonary vein division during right lobectomy may lead to severe haemorrhage or improper 
ligation of drainage veins may result in oedema, which can increase the surgical morbidity or may even be life threatening if the surgeon overlooks the anomalies [26]. In the present case, right middle lobar vein was observed to exit independently in 7 cases out of which 3 were seen to drain into right inferior pulmonary vein thus carrying the risk of severe haemorrhage during lobectomy surgery while the remaining 4 middle lobar veins might have a separate ostium which might initiate paroxysmal atrial fibrillation.

Sathidevi [27] observed that the patterns of bronchopulmonary segments are very variable and reported $59 \%$ of right sided variation as opposed to $41 \%$ on the left side. The present study observed the variations of bronchi in $26.19 \%$ right hilum and $21.62 \%$ left hilum however detailed study of the bronchopulmonary segments was not carried out in the present study.

\section{CONCLUSION}

From the results of the present study and their comparison with the previous studies, it can be concluded that a variety of variations in the lung morphology with respect to the shape, fissures and lobes as well as the hilar structures can occur and that the wide range of these variations occurring among different populations may have a genetic or environmental factors or both affecting their development. Moreover, such variations may contribute to bizarre and misleading clinical presentations of lung pathologies and may even cause paroxysmal atrial fibrillation. Thus, knowledge of the frequency of occurrence of these different variations in a particular population will help the radiologists and clinicians to make correct diagnosis and also the surgeon to perform appropriate surgical procedure with minimal morbidity and mortality. The findings of the present study will contribute to the database for Indian population for better diagnosis and management of pulmonary and even cardiac cases.

\section{Conflicts of Interests: None}

\section{REFERENCES}

[1]. Muresian H. Pluera, lungs, trachea and bronchi In: Standring S, Gray's Anatomy. The Anatomical Basis of Clinical Practice. $41^{\text {st }}$ ed. Elsevier Limited, UK, 2016: 953-969.
[2]. Rosse C, Gaddum-Rosse P. Thorax. In: Hollinshed's Textbook of Anatomy. Lipincott Williams \& Wilkins, Philadelphia, 1997:441-61.

[3]. Meenakshi S, Manjunath KY, Balasubramanyam V. Morphological variations of the lung fissures and lobes. Indian J Chest Dis Allied Sci. 2004; 46(3):179182.

[4]. Magadum A, Dixit D, Bhimalli S. Fissures and lobes of lung - an anatomical study and its clinical significance. Int J Cur Res Rev. 2015; 7(3): 8-12.

[5]. Godwin JD, Tarver RD. Accessory fissures of the lung. Am J Roentgenol. 1985; 144(1):39-47.

[6]. Aldur MM, Denk CC, Celik HH, Tascioglu AB. An accessory fissure in the lower lobe of the right lung. Morphologie. 1997; 81: 5-7.

[7]. Ariyurek OM, Gulsun M, Demirkazik FB. Accessory fissures of the lung: evaluation by high-resolution computed tomography.Eur Radiol. 2001; 11: 24492253.

[8]. Craig SR, Walker WS. A proposed anatomical classification of the pulmonary fissures. J R Coll Surg Edinb. 1997; 42:233-4.

[9]. George BM, Nayak SB, Marpalli S. Morphological variations of the lungs: a study conducted on Indian cadavers. Anat Cell Biol. 2014; 47:253-258.

[10]. Medlar EM. Variations in interlobar fissures. Am J Roentgenol Radium Ther. 1947; 57: 723-725.

[11]. Lukose R, Paul S, Sunitha, Daniel M, Abraham SM, Alex $\mathrm{ME}$, et al. Morphology of the lungs: Variations in the lobes and fissures. Biomedicine. 1999; 19: 227-232.

[12]. Prakash, Bharadwaj AK, Shashirekha M, Suma HY, Krishna GG, Singh G. Lung morphology: a cadaver study in Indian population. IJAE. 2010; 115:235240

[13]. Quadros LS, Palanichamy R, D'souza AS. Variations in the lobes and fissures of lungs - a study in South Indian lung specimens Eur. J. Anat. 2014; 18 (1): 1620.

[14]. Nene AR, Gajendra KS, Sarma MVR. Lung lobes and fissures: a morphological study. Anatomy. 2011; 5: 30-38.

[15]. Larsen WJ. Human Embryology. Churchill Livingstone, New York, 1993: 111-30.

[16]. Richards JMJ, Dunning J, Oparka J, Carnochan FM, Walker WS. Video-assisted thoracoscopic lobectomy: The Edinburg posterior approach. Annals of Cardiothoracic Surgery. 2012; 1(1).

[17]. Waldhausen JA, Pierce WS, Campbell DB. Thoracic Surgery. In: Surgery of the Chest. $6^{\text {th }}$ ed. Mosby, St Louis, Missouri, 1996:134.

[18]. Pimpec-Barthes F L, Arame A, Pricopi C, Riquet M. Prevention of middle lobe torsion or bronchial plication using anti-adhesive membrane: a simple, safe and uncomplicated technique. Eur J Cardiothoracic Surg. 2011; 39(6):1059-1069.

[19]. Tarver RD. How common are incomplete pulmonary fissures, and what is their clinical significance? AJR Am J Roentgenol.1995; 164(3):761.

[20]. Murlimanju BV, Massand A, Madhyastha S, Pai MM, Prabha LV, SaralayaVV. Anatomical variations of 
arrangement of structures at the pulmonary hilum: a cadaveric study. Surgical and Radiologic Anatomy. 2017; 39(1):51-56.

[21]. Matsumoto K, Yamasaki N, Tsuchiya T, Miyazaki T, Tomoshige $\mathrm{K}$, Hayashi $\mathrm{H}$, et al. Three-dimensional computed tomography for a mediastinal basal pulmonary artery. The Annals of Thoracic Surgery. 2012; 94(5): 115-116.

[22].Subotich D, Mandarich D, Milisavljevich $M$, Filipovich B, Nikolich V. Variations of pulmonary vessels: some practical implications for lung resections. Clin Anat. 2009; 22: 698-705.

[23]. Rajeshwari MS, Ranganath P. Variations in Draining Patterns of Right Pulmonary Veins at the Hilum and an Anatomical Classification. ISRN Pulmonology.2012:1-4.

[24]. Thorning C, Hamady M,. Liaw JV, Juli C, Lim PB, Dhawan $\mathrm{R}$ et al. CT evaluation of pulmonary venous anatomy variation in patients undergoing catheter ablation for atrial fibrillation, Clin Imaging. 2011; 35(1):1-9.
[25]. Marom E, Herndon J, Kim Y, McAdams HP. Variations in pulmonary venous drainage to the left atrium: implications for radiofrequency ablation, Radiology. $2004 ; 230(3): 824-829$.

[26]. Sugimoto S, Izumiyama O, Yamashita A, Baba M, Hasegawa T. Anatomy of inferior pulmonary vein should be clarified in lower lobectomy. The Annals of Thoracic Surgery. 1998; 66(5):1799-1800.

[27]. Sathidevi VK. Anatomical arrangement of the lobar bronchi, bronchopulmonary segments and their variations. Int J Res Med Sci. 2016; 4(11):4928-4932.

How to cite this article:

Subhalakshmi Wahengbam, Huidrom Rajshree Devi, Gurumayum Tarunkumar Sharma, Gaining Gangmei, Ningthoujam Debashree Devi. MORPHOLOGICAL STUDY OF HUMAN LUNGS. Int J Anat Res 2019;7(2.1):6345-6352. DOI: 10.16965/ijar.2019.115 